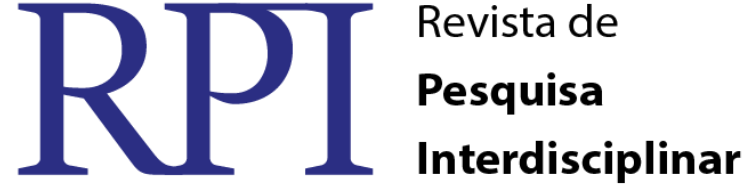

\section{AS TECNOLOGIAS DA INFORMAÇÃO E SUAS IMPLICAÇÕES PARA A EDUCAÇÃO ESCOLAR: UMA CONEXÃO EM SALA DE AULA}

\author{
Graciele Alencar Dias - UFCG ${ }^{1}$ \\ Rosiane de Alencar Cavalcanti - UFCG ${ }^{2}$
}

\begin{abstract}
RESUMO
O século XXI é marcado por grandes mudanças e avanços tecnológicos, oferece percursos inovadores, seja nas práticas sociais, educacionais, culturais, enfim, no relacionamento com a sociedade. Assim, neste artigo propomos mostrar como se tem dado a conexão entre o ensino e as tecnologias de informação na sala de aula, buscando compreender as implicações do meio digital para a educação escolar. A internet pode funcionar como um atrativo a ser incorporado às estratégias de ensino na linguagem hipermídia, abrindo espaço para uma maior interação mediada pelos gêneros eletrônicos através da interdisciplinaridade. A escola necessita abordar um novo paradigma de ensino para suprir as necessidades existentes, por meio de gêneros digitais e uma linguagem multimodal e multifuncional, para isso exige-se um "letramento digital". Os professores precisam repensar a sua prática de ensino e as estratégias que devem ser empregadas para auxiliar no processo docente. $\mathrm{O}$ presente trabalho evidencia que o uso dessas tecnologias desperta a reflexão e a autonomia crítica do educando. Portanto, é inquestionável a necessidade da adesão escolar à educação digital, por meio do acesso às informações e a inter-relação das teorias educacionais, criando e proporcionando um alicerce de linguagem universal, implicando assim uma realidade de ensino contextualizada, já que transforma o aprendizado do aluno, inserindo-o como sujeito social na prática educacional e na tecnologia simultaneamente. Utilizaremos como suporte teórico as postulações de autores como MULLER (2005); MARCUSCHI (2004); SILVA (2005), face aos estudos das Orientações Curriculares para o Ensino Médio (2006) entre outros, que discutem sobre a relevância e as implicações da tecnologia para a educação escolar.
\end{abstract}

Palavras-Chave: Tecnologia de informação; educação escolar; difusão digital.

\section{INFORMATION AND COMMUNICATION TECHNOLOGIES AND THEIR IMPLICATIONS FOR SCHOOL EDUCATION: A CONNECTION IN THE CLASSROOM}

\begin{abstract}
\footnotetext{
${ }^{1}$ Universidade Federal de Campina Grande- gracieledias@ hotmail.com

${ }^{2}$ Universidade Federal de Campina Grande- rosianealencar2010@hotmail.com
}

The 21 st century has been marked by great changes and technological advances, hence it has offered innovative courses, in social practices, educational, cultural, and in the relationship with society. Therefore in this article we propose to discuss how the connection between teaching and Information and Communication Technology (ICT) in the classroom has happened, trying to understand the implications of digital media for school education. The internet can function as an appealing resource to be incorporated into the teaching strategies in hypermedia language, making room for greater interaction mediated by electronic genres through interdisciplinarity. Schools need to address a new 
teaching paradigm to cope with students' existing needs, through digital genres and a multi-modal and multi-functional language, for doing so it is required "digital literacy". Teachers need to rethink their teaching practices and strategies that should be employed to assist in the teaching process. This study shows that the use of ICT arouses the students' reflection and critical autonomy. Therefore, it is unquestionable the need of the school joining the digital education, through access to information and the interrelation of educational theories, creating and providing a foundation of universal language, thus implying a contextualized teaching reality, since it transforms students' learning, providing them with opportunities to be social subjects in the educational and technological practice simultaneously. We will use as theorical support postulations of some authors like MULLER (2005); MARCUSCHI (2004); SILVA (2005), in accordance to studies of the Curriculum Guidelines for Secondary Education (2006) among others who discuss the relevance and implications of technology for education.

Keywords: Information technology; School education; Digital diffusion.

\section{INTRODUÇÃO}

A internet tem um papel fundamental na mudança de hábitos e de relacionamentos, criando um ambiente de ludicidade e de formação de identidades, vem sendo retratada como um novo espaço de atividade humana, seja nas práticas sociais, educacionais, culturais, enfim, no relacionamento com a sociedade. É uma esfera discursiva, através da interação virtual intercedidos pelos gêneros eletrônicos ou digitais, segundo Marcuschi (2004, p. 19) tal esfera "transmuta de maneira bastante complexa gêneros existentes, desenvolve alguns realmente novos e mescla vários outros".

A tecnologia assume vida própria e compõe uma identidade analógica do homem contemporâneo com as novas tecnologias de informação e comunicação em que são utilizadas como recurso cultural e de desenvolvimento social. Promove uma situação dialógica virtual, já que os gêneros digitais instituem relações prazerosas entre os usuários e a linguagem.

A rede mundial surgiu no ano de 1962, em plena Guerra Fria, "foi durante a Segunda Guerra Mundial e no período seguinte que se deram as principais descobertas tecnológicas em eletrônica” (CASTELLS, 1999, p. 58) com propósitos militares, já que qualquer inovação nos meios de comunicação asseguraria disputa da liderança das potências União Soviética e pelos Estados Unidos sobre o mundo, para as forças armadas norte-americanas terem acesso às informações caso a oposição destruísse as telecomunicações, hoje tratadas como convencionais. Assim era necessário criar uma rede, Arpanet, criada pela ARPA, em 1969, rede nacional de computadores designada para certificar a segurança em caso de acidentes de 
comunicações, consentindo o compartilhamento de recursos. Apenas em 1972 que o governo americano abriu espaço para a sociedade, divulgando o projeto revolucionário.

O advento da rede mundial através da sua positividade em meados de 1970 e 1980 serviu também como informação para o meio acadêmico. Quando o termo tornou-se um meio de comunicação. No Brasil, a rede surgiu em 1988. A internet disseminou-se somente em 1990, através da sua popularidade, por conta disso, surgiram vários navegadores, a exemplo, a Internet Explorer da Microsoft e o Netscape Navigator.

A partir de 2006, as redes sociais ganharam espaço na vida de cada usuário, por ser interação social, sendo pioneiro o Orkut, hoje a preferência são de outras redes, como Facebook, Blog, WhatsApp, Twitter, Instagram, Imo, entre outros. No ano de 2010, os portais de serviços online com sites de compras coletivas começam a surgir com maior intensidade para facilitar as aquisições entre consumidores e empresas, além de fazer com que os consumidores não percam tempo em pontos comerciais.

Seria irrefutável negar como a tecnologia faz parte do nosso meio sem nos darmos conta, existe em grande escala à difusão de dados e informações para o mundo. No Brasil, são prestados inúmeros serviços sem a necessidade de deslocamento do ambiente em que o usuário se encontra, como fazer compras de múltiplos produtos no comércio eletrônico, ter acesso a serviços bancários, correios eletrônicos, sistemas governamentais de informação, cursos profissionalizantes, graduações e pós-graduações via online, sites de relacionamento e de auto ajuda. Vivemos numa sociedade informacional e tecnológica em que ocorre mudanças em aglomeradas esferas sociais.

Com o passar do tempo, a tecnologia além de promover a difusão digital é também um meio de aderência social, possibilita flexibilidade no manuseio desse recurso que contribui para pensamentos e atitudes inovadoras. Para Muller (2005, p. 19) é "necessário entendermos a inclusão digital associada à inclusão social. É preciso, também, possibilitar a reflexão sobre que tipo de informação e de conhecimento o sujeito/aluno precisa para a resolução dos problemas em sua vida".

Assim, nessa perspectiva, podemos perceber que os novos recursos tecnológicos impõem ao tempo a velocidade do movimento e o acesso a meios mais rápidos de mobilidade. Tal mobilidade constitui-se como uma potente ferramenta de poder e dominação. 


\section{Tecnologia conectada na sala de aula}

O ambiente digital surge como uma nova perspectiva no contexto escolar, abrindo espaço para uma maior interação humana mediada pelos gêneros eletrônicos, através da interdisciplinaridade. A linguagem universal e compartilhada no mundo inteiro, transforma o aprendizado do aluno, inserindo-o como sujeito social no contexto educacional e na tecnologia simultaneamente. Como afirma Muller (2005, p. 19):

... a escola deve buscar inovação, pois está inserida em uma sociedade em que a tecnologia avança rapidamente e a distância entre os que têm e os que não têm acesso ao computador, com conexão à rede mundial, cresce a cada dia. No mundo contemporâneo, onde as tecnologias de informação e comunicação ainda não chegam à maior parte da população do planeta, em que pese o ritmo veloz de sua disseminação, precisamos diminuir essa distância, entre os mais e os menos favorecidos economicamente. Esse é um dos papéis da escola, que tem como objetivo/meta, no seu Projeto PolíticoPedagógico, a formação de cidadãos pensantes, críticos e criativos.

A adesão escolar precisa está suscetível no que se diz respeito às tecnologias educacionais, objetivando uma educação de qualidade e informatizada, para isso é preciso rever as diretrizes curriculares abordando a inclusão digital, uma vez que a internet desenvolve diversas aptidões no tocante ao ensino aprendizagem do educando. Como afirma (MULLER, 2005, p. 18):

A discussão sobre a inclusão digital e escola pública, com a implantação da Informática aplicada à Educação, pressupõe estabelecer conexões entre as diretrizes nacionais, estaduais, municipais dos Planos de Educação e dos Projetos Políticos das escolas. Além disso, é necessário pensar a reformulação do currículo, o tempo, a organização e o aproveitamento do espaço escolar, bem como a implementação de aprendizagem por projetos.

Para tanto é importante conhecer as particularidades da realidade escolar e assim introduzir diferentes tecnologias na escola: computador, vídeos, internet, data show, aparelho de som, TV, entre outros recursos que sejam positivos na prática pedagógica. A aprendizagem necessita ser desafiadora, com vistas a compreender o mundo e atuar na própria 
rede de conhecimentos, buscando desenvolver nos alunos as aptidões. Deve-se incluir nessa jornada o aprendizado sobre o uso correto de editores de textos, o Excel, programas, sites para pesquisa, e antes de tudo dar ênfase à escrita seja manual ou digital, ambas têm as suas prioridades, cada uma a seu modo, o uso do editor de textos promove a conexão de distintas formas de expressão, já que associa texto, imagem, fluxogramas, uso de autoformas, gráficos entre outros, além disso, é um suplemento na correção ortográfica.

\begin{abstract}
A pesquisa pode ser um componente muito importante na relação dos alunos com o meio em que vivem e com a ciência que estão aprendendo. A pesquisa pode ser instrumento importante para o desenvolvimento da compreensão e para explicação dos fenômenos sociais. (Orientações Curriculares para o Ensino Médio, 2006, p. 125 e 126).
\end{abstract}

A escola necessita abordar um novo paradigma de ensino para suprir as necessidades existentes, por meio de gêneros digitais e uma linguagem multimodal e multifuncional, no entanto, para isso exige-se um "letramento digital" como aborda Marcuschi (2004) para abraçar os desafios da sociedade moderna.

Os professores precisam de habilidades no campo da tecnologia de informação, é necessário repensar a sua prática docente deixando abrir espaço para um novo saber. O papel do professor nesse novo contexto educacional é dá subsídios para que o aluno adquira uma postura autônoma e crítica com total responsabilidade e assim aprenda de forma correta a manejar a tecnologia de informação. Como afirma Leopoldo "As novas tecnologias surgem com a necessidade de especializações dos saberes, um novo modelo surge na educação, com ela pode-se desenvolver um conjunto de atividades com interesses didático-pedagógica”. (2004, p.13). Então é justamente nesse momento que envolve a relação do educador e educando, nesse papel tão decisivo, que o orientador influencie o aluno de forma positiva e que consiga desenvolver sujeitos conscientes para a alfabetização tecnológica.

As práticas de relacionamento social eletrônico como o uso das redes sociais estão cada vez mais corriqueiras na vida dos alunos, principalmente o uso do Facebook, (site e serviço de rede social que traz um perfil pessoal no qual se adiciona usuários. Possibilita conversar com os amigos através de mensagens, Compartilhar vídeos, fotografias, links para todos os usuários ou para grupos fechados) do WhatsApp, (aplicativo multiplataforma, possibilita chamada de voz, conversas escritas, compartilhar informações através de vídeos, imagens e áudios) do email,(endereço virtual, que significa electronic mail — ou seja, correio RPI Revista de Pesquisa Interdisciplinar, Cajazeiras, v. 1, Ed. Especial, 160 - 167, set/dez. de 2016. 
eletrônico) de blogs (diário da web). assim, percebe-se a importância de se trabalhar esse tema de forma educativa, consciente e de maneira plausível para todos.

Para MARCUSCHI (2004, p.28-29) “o endereço eletrônico está na lista dos gêneros mais conhecidos e que vêm sendo estudados no momento". Deste modo, a comunicação pelas redes sociais ganham cada vez mais espaço. Por isso é de grande importância se trabalhar na sala de aula a comunicação digital, os alunos já estão aptos na colocação desse recurso, então nada melhor do que aliar o conteúdo com o que desperta o interesse e a curiosidade do mesmo.

E é nessa abertura de conexão coletiva e social, com o ser e o mundo digital que abre espaço para o ciberespaço, ou seja, garante a informatização no espaço de comunicação. A formação de espaços virtuais para a comunicação midiática configura uma nova sociedade contemporânea, assumindo uma nova cultura, emitindo a cibercultura, "a cultura contemporânea marcada pelas tecnologias digitais.” (LEMOS, 2003, p. 12). Toda essa atração virtual se dá pela sua flexibilidade da riqueza semiótica (som-imagem- escrita) congregada a tela digital do computador.

Independente do gênero digital nas novas formas de interação pela sua subordinação e características próprias no mundo virtual, é importante lembrar que ao utilizar os meios tecnológicos a escrita prevalece, apesar de haver uma conexão entre recursos visuais e sonoros, as ações na web se dão por escrito, dependem incondicionalmente da leitura e escrita, menos em programas que é possível visualizar a imagem como em câmeras e em telefones por ser possível falar. Como afirma Marcuschi (2004, p.18) "Um dos aspectos essenciais da mídia virtual é a centralidade da escrita, pois a tecnologia digital depende totalmente da escrita".

A internet é uma grande aliada na escola, seja como fonte de pesquisa ou para lazer, no entanto, devemos estar atentos na busca da facilidade desses mecanismos, é importante ter sempre o cuidado com a escrita manual, até porque nem sempre temos a nossa disposição um computador que possa nos auxiliar na autocorreção. Portanto, prejuízos também perpassam na escrita digital, a falta de preocupação com a ortografia, pelas suas funções de autocorreção gramatical e linguística, logo as pessoas serão deficientes nesse setor, a estética da letra manual também está cada vez mais defasada, e por último o famoso plágio. As pessoas muitas vezes esquecem que a internet é um meio de promover as informações, por ser uma biblioteca digital e acabam deixando de pensar, raciocinar por ser mais fácil "pegar o pronto e acabado". 
Segundo Valente (1998, p. 12), “o computador não é mais o instrumento que ensina o aprendiz, mas a ferramenta com a qual o aluno desenvolve uma tarefa por intermédio do computador". Sem dúvida, o uso do computador é de grande importância, mas devemos ter a capacidade de pensar e agir para resolver problemas sem a ajuda da máquina. Deste modo, a escrita manual e a escrita digital devem caminhar juntas como ferramentas integrantes na educação.

É importante lembrar que o computador, hoje é fundamental na vida de educadores e educandos, mas de forma acessória, não como forma principal para aquisição de conhecimentos, o professor /orientador não pode ser substituído pela máquina porque é através dele que o aluno encontrará respostas mais humanas e adequadas a sua realidade. As mudanças tecnológicas, tão enfáticas e mais acessíveis nos dias de hoje devem funcionar como suporte para a ampliação da visão adquirida em sala de aula através do dialogo professor/aluno, esse intercâmbio "cara-a-cara" a máquina nunca vai substituir. Os alunos apesar de possuírem um bom domínio necessitam da orientação do educador, o computador oferece inúmeras opções e respostas, muitas delas sem um fundo de verdade, assim, o professor bem preparado é exclusivo e insubstituível e sua interação com os alunos é única.

Assim, a tecnologia representa um obstáculo ou um aliado para a educação? Tudo isso vai depender da maneira como a pessoa emprega esse recurso no cenário educacional, já que assume transformações éticas e culturais na vida dos usuários. Mas, de fato é um grande aliado no processo de comunicação e aprendizado, para Silva (2005, p. 63) "o uso da Internet na escola é exigência da cibercultura, isto é, do novo ambiente comunicacional-cultural que surge com a interconexão mundial de computadores em forte expansão no início do século XXI".

\section{Considerações Finais}

A revolução de informação na prática educacional passou por transformações positivas, através da internalização do processo de comunicação no meio digital, visto que o homem cria e dar os comandos dessa máquina de acordo com as suas necessidades, instituindo novas formas de interação em todas as esferas da vida. Demanda igualmente mudanças sociais no processamento simultâneo dialógico, como também implica novas 
perspectivas no contexto escolar para que se possam desenvolver sujeitos conscientes para a alfabetização tecnológica.

A escola precisa está articulada nessa nova totalidade informacional, a comunicação pela rede social ganha cada vez mais espaço, por isso é de grande importância se trabalhar na sala de aula a comunicação digital trazendo para escola a vivência cotidiana como uma nova ferramenta e que pode causar maior impacto, interesse e curiosidade dos alunos, com vista a tecerem a própria rede de conhecimentos.

Deste modo, as inovações tecnológicas auxilia a cooperação, o raciocínio e ensina a buscar soluções por meio do acesso a informações e a inter-relação de distintas tecnologias. A tecnologia deve está incorporada ao processo educacional, para que a escola possa acompanhar os ritmos da sociedade e então acolher os alunos com todas as suas peculiaridades, transformando-os em sujeitos pensantes e críticos. Portanto, a pretensão é unir o processo de ensino aprendizagem com as novas tecnologias usadas na sala de aula para descobrir novas aptidões.

\section{REFERÊNCIAS}

CASTELLS, Manuel. A sociedade em rede - a era da informação: economia, sociedade e cultura; v. 1. São Paulo: Paz e Terra, 1999.

LEMOS, André. “Cibercultura. Alguns pontos para compreender a nossa época”. In: \& Cunha, Paulo (orgs). Olhares sobre a Cibercultura. Porto Alegre, Sulina, 2003; pp. 11-23.

LEOPOLDO, Luís Paulo. Novas Tecnologias na Educação: Reflexões sobre a prática. Formação docente e novastecnologias. LEOPOLDO, Luís Paulo-Mercado (org.). -Maceió: Edufal, 2002. Cap. 1 Leopoldo, Luís Paulo/Formação docente e novas tecnologias. 2004.

MARCUSCHI, L. A. "Gêneros textuais emergentes no contexto da tecnologia digital.” In: \& XAVIER, A. C. (Orgs.) Hipertexto e gêneros digitais: novas formas de construção de sentido. Rio de Janeiro: Lucerna, 2004, p. 13-67.

MULLER, Sílvia Ambrósio Pereira. Tese (Mestrado)Inclusão Digital e Escola Pública: uma análise da ação pedagógica e da informática na educação.Porto Alegre, 2005.

Orientações Curriculares para o Ensino Médio. Volume 3: Ciências Humanas e suas tecnologiasBrasília-2006. Ciências humanas e suas tecnologias/ Secretaria de Educação Básica. - Brasília: Ministério da Educação, Secretaria de Educação Básica, 2006.

SILVA, Marco. In Internet na escola e inclusão. Integração das tecnologias na Educação/secretaria de Educação a Distância. Brasília: Ministério da Educação, Seed. 2005. 